\title{
Removal of Oxide Layer on Metal Surface by Vacuum Arc
}

\author{
Koichi Takeda and Sunao Takeuchi ${ }^{\dagger}$ \\ Advanced Technology Research Laboratories, Nippon Steel Corporation, Kawasaki 211, Japan
}

\begin{abstract}
The interesting properties of cathode spots were investigated in the removal of an oxide layer on metal surface by a vacuum arc. The cathode spots attack the oxides selectively and remove them by evaporation. The observed removal rate of the oxide layer increases in proportion to the arc current and in inverse proportion to the thickness of the oxide layer. Considering the energy balance at the cathode spot, the authors have developed a simplified model to predict the removal rate. The theoretical results agree with the experimental ones qualitatively. The modeling reveals that there exists a critical current density below which the removal of oxides does not occur.
\end{abstract}

(Received February 12, 1997)

Keywords: vacuum arc, cathode spot, oxide layer, descaling, surface cleaning

\section{Introduction}

Recently, the words "vacuum arc" are often used. But the definition of the terms is not clear. Strictly speaking, they are contradictory in terms. Any electric arc cannot exist in a vacuum, as there is no medium to maintain a discharge. They are generally used for the arc which burns at a very low pressure and is sustained in gases created by the evaporation of cathode materials. A vacuum arc is characterized by (1) a multitude of arc spots on the cathode which are called "cathode spots", (2) vapor emission of a cathode material due to the extremely intense power density at the cathode spot, and (3) rapid movement of the spots over the cathode surface in a random manner ${ }^{(1)}$.

The history of studies on vacuum arcs is not new. In early work ${ }^{(2)-(4)}$ researchers concentrated their studies on the understanding of the arc in vacuum switches used for the interruption of an electric current in a high voltage circuit. In the vacuum switch, the erosion of contact electrodes by the arc was a grave problem, therefore suppression or immediate extinction of the arc was a major interest. A vacuum arc has also been used in film deposition processes to evaporate a target material and to form a highly ionized and energetic plasma ${ }^{(5)-(7)}$. In these applications, the arc is terminated on a clean metal surface. Therefore, little has been investigated on the arc burns on a oxide layer ${ }^{(8)}$.

Only a few reports deal with the cleaning action of the cathode spots in the process of plasma spraying ${ }^{(9)-(12)}$. Arc cleaning was recognized as a useful pretreatment to obtain a coating with strong adhesion in low-pressure plasma spraying. Recently, removal of a thick oxide layer from the metal substrate, which is often called "descaling", is attempted by using vacuum arcs ${ }^{(13)}$. In cleaning or descaling by the arc, it was observed that cathode

$\dagger$ Present address: New Materials Division, Nippon Steel Corporation, Tokyo 100-71, Japan. spots were formed selectively on an oxide rather than on a metal, and an oxide layer at the spot was removed by evaporation ${ }^{(9)}$. However, the knowledge on the descaling action by the cathode spots is available to a limited extent. It has not been clear why the cathode spots attack selectively to the oxide. One possible reason for the selectivity is due to the deference in work functions between a metal and its oxide. The electron emission from the cathode is governed by the work function, the value of which represents the magnitude of an energy barrier for electron emission from a material surface to a vacuum. Therefore, it is likely to form a cathode spot preferably on a material with a smaller work function. In most cases, the work function of a metal is larger than that of its oxide. As a result, the cathode spots may look for oxides, automatically stay on them and may not move to a metal surface until all of the oxides are removed away from the cathode surface. Owing to the high density of the energy flux at the cathode spot, the oxide layer under the spot is heated up to a vaporization temperature and is evaporated from the surface in a short time.

A greater understanding of such unique behavior of the vacuum arc requires further investigation. The authors studied the fundamental properties of the cathode spots which were generated at a low pressure on a stainless steel covered with a thick oxide layer. Simplified modeling on the removal rate of the oxide layer was developed and the predicted results was compared with experiment.

\section{Experimental Procedure}

As shown in Fig. 1, an experimental setup was composed of a vacuum chamber with electrodes inside, a DC power supply connected with the electrodes, an evacuation system with a rotary pump, a water circulation system to cool an anode and equipment for measurements. A test piece was made of SUS430 stainless steel, the surface of which was covered with an oxide layer. Its dimensions were $100 \mathrm{~mm}$ in length and $200 \mathrm{~mm}$ in width, respec- 


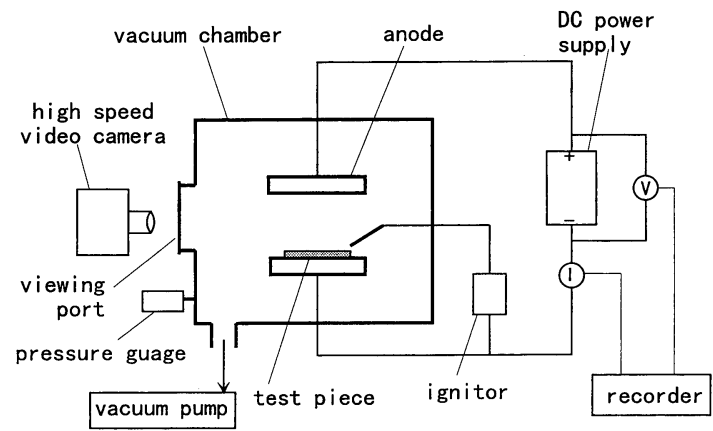

Fig. 1 Schematic illustration of the experimental setup for vacuum arc descaling.

tively. It was connected with a negative polarity of the power supply and served as a cathode. The power supply was operated in a constant current mode usually and in some cases in a pulse mode. The open circuit voltage of the power supply was $200 \mathrm{~V}$. The magnitude of an arc current was adjusted at a certain amperage between 50 and $400 \mathrm{~A}$, depending on the experimental condition. The anode was a water cooled copper disc with a diameter of $200 \mathrm{~mm}$. An arc started with the help of a high voltage RF igniter. The pressure in the vacuum chamber was reduced to $10 \mathrm{~Pa}$ before the arc ignition. When the arc burns, it increased to $50 \mathrm{~Pa}$ or higher because of the evaporation of the cathode material and the release of various gases inside the chamber. The distance between the anode and the cathode (test piece) was kept $100 \mathrm{~mm}$. During the arc burning, multiple tiny cathode spots formed on the surface of the test piece and moved in a random manner. The number and the movement of the cathode spots were visually observed through the windows of the chamber and recorded by a high speed video camera (NAC HVS-200). Time resolution of the video recorder was $5 \mathrm{~ms}$. The variations in arc voltage and arc current were monitored during the experiment. The pressure inside the chamber and temperature increase in the cooling water were also recorded.

The surface of the test piece eroded by the cathode spots was examined using SEM (scanning electron microscopy), EPMA (electron probe microanalysis) and GDS (glow discharge emission spectroscopy).

\section{Experimental Results}

\section{Removal of oxide layer by cathode spots}

The changes in the surface of the test piece by the vacuum arc treatment are shown in Fig. 2. Initially the surface was completely covered with an oxide layer of $5 \mu \mathrm{m}$ in thickness, as shown in Fig. 2(a). On descaling, the cathode spots left the tracks of their movement on the surface as shown in Fig. 2(b). Figure 2(c) represents the metallic surface after the completion of the descaling. A branch of the tracks shown in Fig. 2(b) was microscopically analyzed by SEM and EPMA. The SEM photograph of the branch and its EPMA images of oxygen are

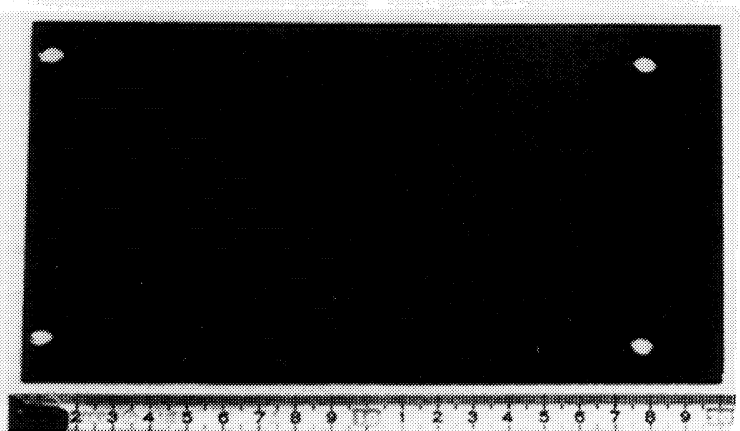

(a) initial surrface

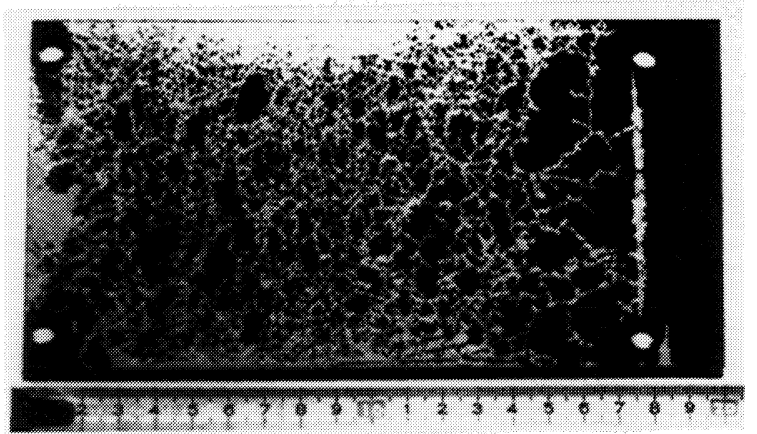

(b) surface during descaling

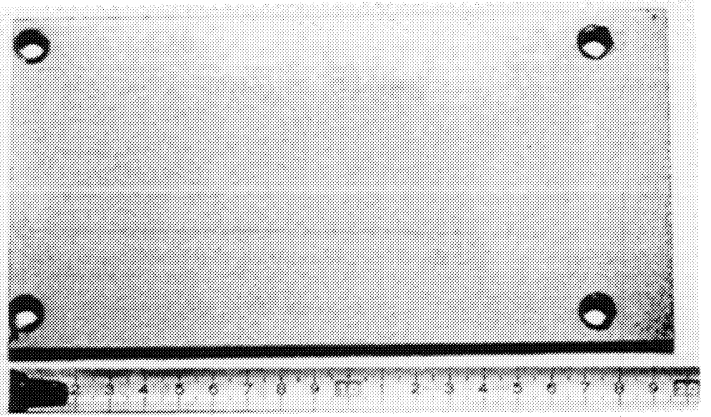

\section{(c) surface after descaling}

Fig. 2 Change of the surface by vacuum arc treatment; (a) initial surface of a stainless steel plate covered with a scale, (b) surface during vacuum arc treatment and (c) surface after descaling by vacuum arc treatment.

shown in Figs. 3(a) and (b), respectively. These figures denote that the removal of the oxide proceeds with the movement of the cathode spots, leaving a series of eroded craters on the surface. The ultra-fine powder of the oxide materials was deposited on the anode and chamber wall. It reveals that the descaling occurs by evaporation.

GDS analyses were also carried out to investigate the change of chemical composition before and after the vacuum arc treatment. Figures 4(a) and (b) show the element distributions in a depth direction from the surface before and after the treatment, respectively. From these figures, it is known that the oxide layer on the surface is removed completely by the vacuum arc treatment.

The descaling rate for a $5 \mu \mathrm{m}$ thick oxide layer is plotted against the arc current in Fig. 5. The rate change with the thickness of the oxide layer is illustrated in Fig. 


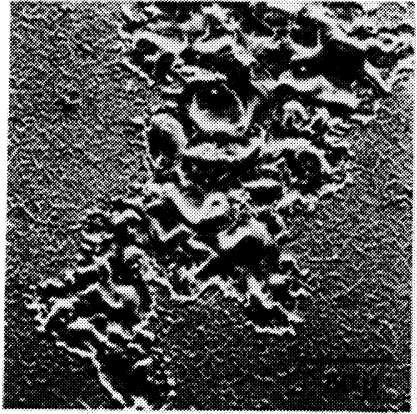

(a)

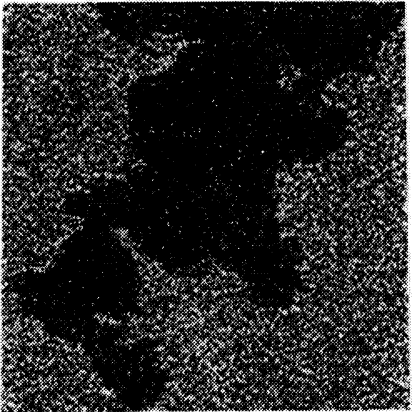

(b)
Fig. 3 Track on the surface eroded by the cathode spot movement; (a) SEM photograph and (b) EPMA image of oxygen.
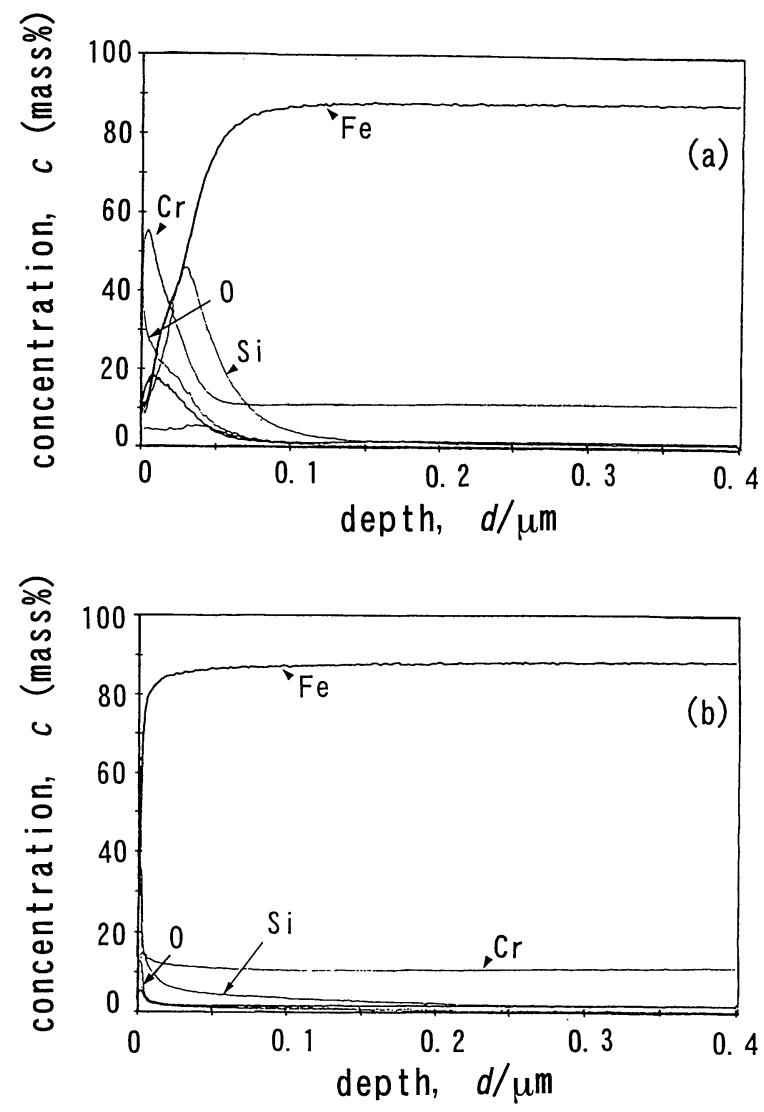

Fig. 4 Change of the chemical composition near the surface obtained by GDS; (a) initial distributions and (b) those after vacuum arc treatment.

6, where descaling was carried out at a fixed arc current of $200 \mathrm{~A}$. Roughly saying, the descaling rate increases proportionally to the total arc current and decreases in inverse proportion to the thickness of the oxide layer.

\section{Current and voltage characteristics in vacuum arc}

The variations in arc current and arc voltage with time are illustrated in Figs. 7(a) and (b), respectively. As shown in these figures, the arc current is kept constant during the arc burning except for a short time just after the ignition. During the descaling action, the arc voltage fluctuates a little. Then, it slightly increases at a certain

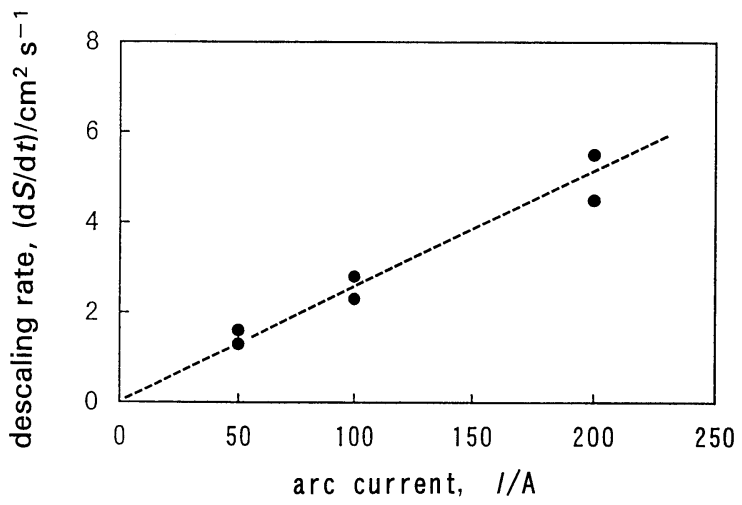

Fig. 5 Change of the descaling rate with the arc current for a scale thickness of $5 \mu \mathrm{m}$.

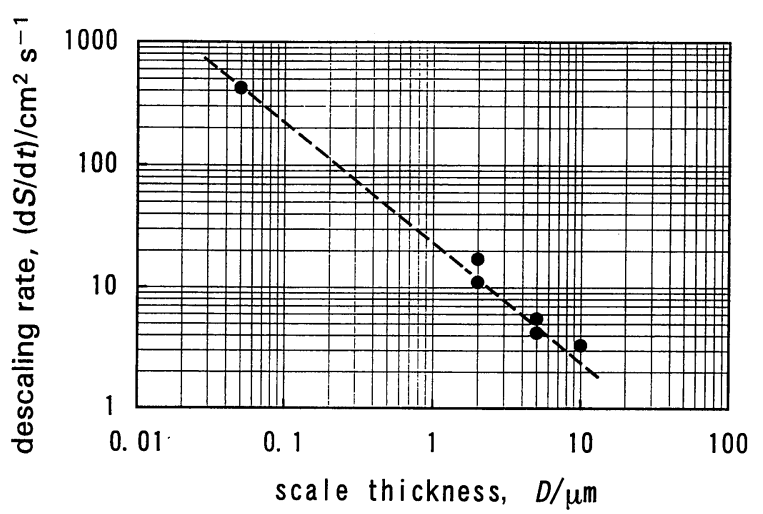

Fig. 6 Change of the descaling rate with the scale thickness at an arc current of $200 \mathrm{~A}$.
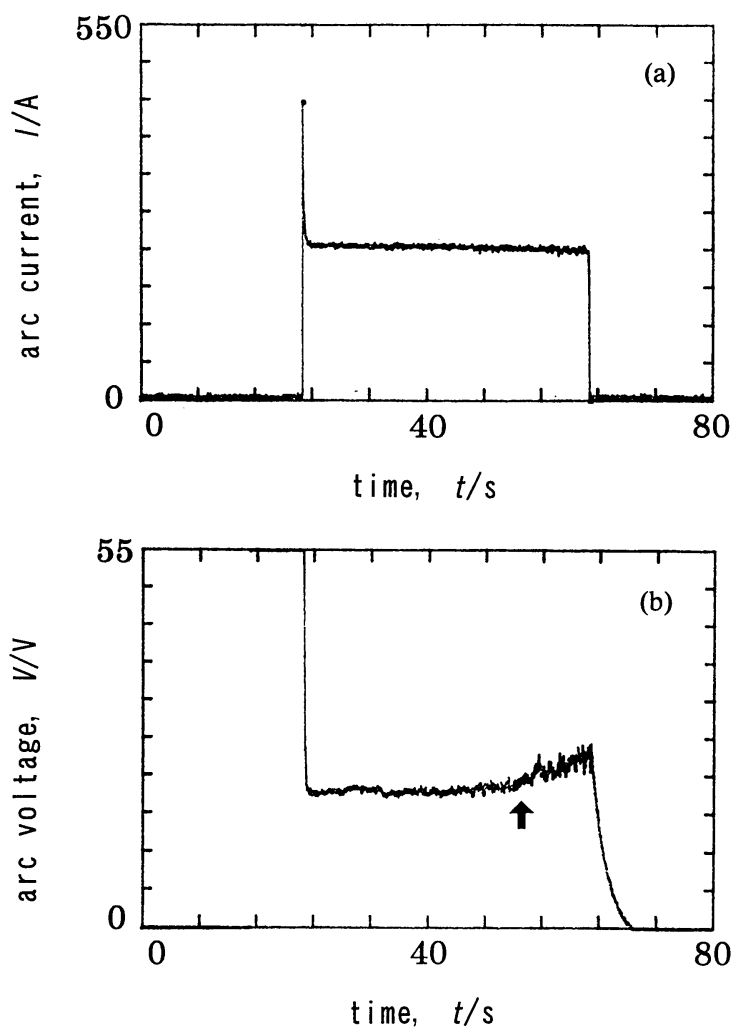

Fig. 7 Current and voltage characteristics of the vacuum arc in a constant current operation. 
time as shown by the arrow in Fig. 7(b). Observation of the test piece surface through the window revealed that the time pointed by the arrow corresponds to the finishing time of the descaling action. Before that time, cathode spots are formed on an oxide and, after that time they are on a metal. The increase in arc voltage is likely to be attributed to the difference of the work function between a metal and its oxide. It is because the voltage increase is almost the same order of the difference in the work function between them. From such a voltage increase, we can determine the time of complete descaling.

\section{Number of cathode spots}

The change of the total arc current results in the change of the spot number, as shown in Fig. 8. From the observation of the cathode spots with a high speed video camera, it was known that creation and extinction of the spots occur very frequently. One spot often splits into two spots and two spots combine together to form one spot. Therefore, the spot number does not constant in a microscopic time scale even if the total arc current is kept constant. However, roughly saying, the number of the

\section{$1=230 \mathrm{~A}$}
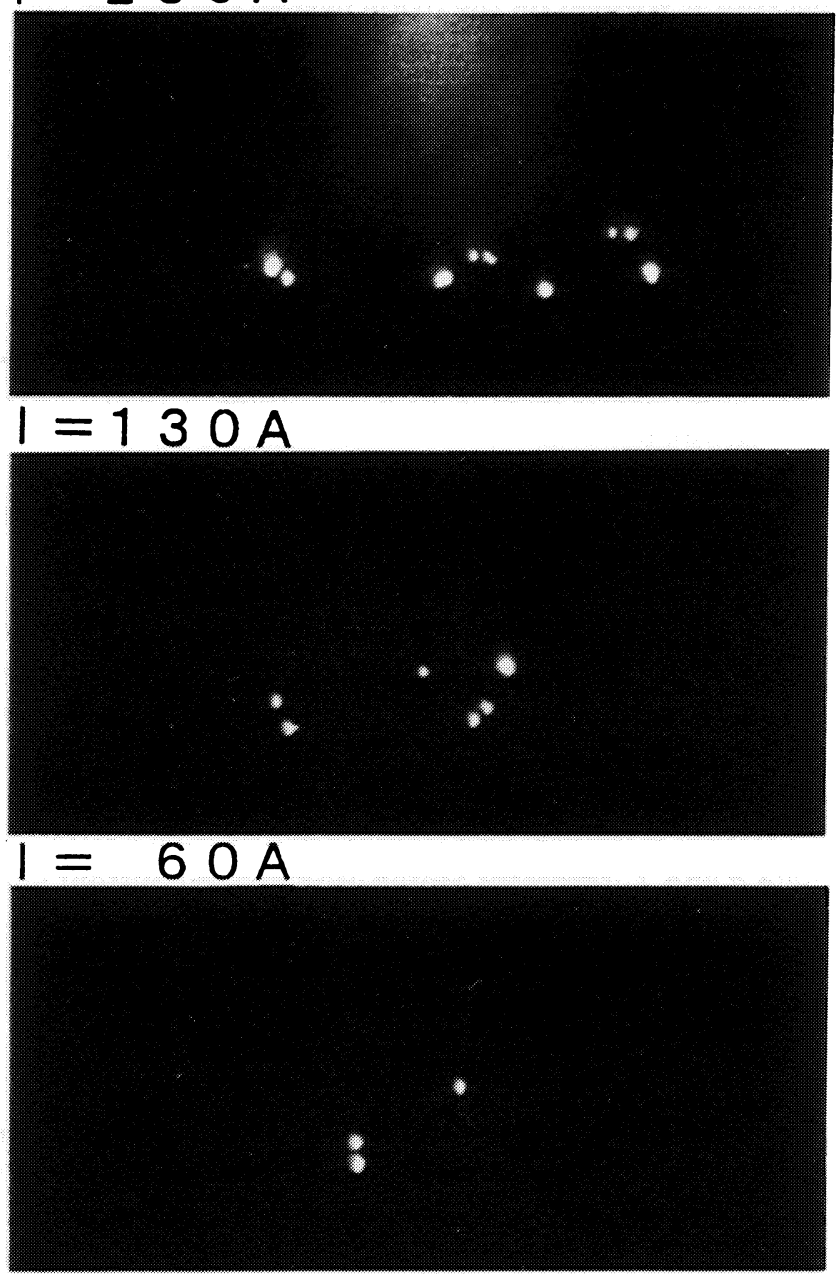

Fig. 8 Photographs of the cathode spots formed on the stainless steel covered with a scale. The number of the cathode spots increases with the increase of the arc current.

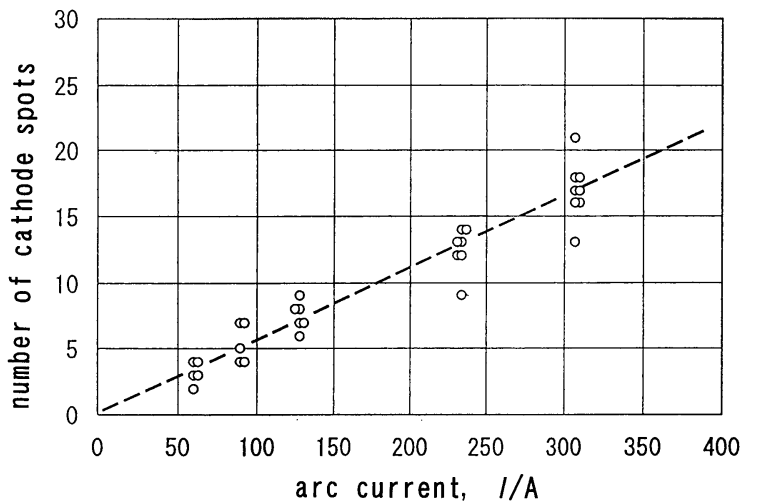

Fig. 9 Change in the number of cathode spots with arc current for the stainless steel covered with scale.

spots varies in proportion to the total arc current as shown in Fig. 9. The arc current per one spot is estimated to be $18 \mathrm{~A}$ on the average when the spots is formed on the stainless steel covered with an oxide layer.

\section{Heat flux at a cathode spot}

As mentioned above, multiple spots are formed on the cathode. The average density of the heat flux at one cathode spot is given by the following relation:

$$
E=\alpha i V / s
$$

where $E, i, V$ and $s$ represent the heat flux density, the arc current, the arc voltage and the area of one cathode spot, respectively. The ratio of cathode input to the total energy supplied into the arc is denoted by $\alpha$. By measuring the temperature difference between inlet cooling water and outlet one, the value of $\alpha$ was estimated to be $1 / 3$.

It is difficult to determine the size of the cathode spot because of its rapid and random motion. In order to estimate the dimension of the spot, the arc burns in a pulse mode and the tracks on the surface eroded by the cathode spots were examined. Figures 10(a) and (b) represent the tracks produced by a short pulse (less than $100 \mu \mathrm{s}$ ) and those by a long pulse (about $10 \mathrm{~ms}$ ), respectively. In Fig. 10(a), the diameters of the craters eroded by the spots lie in the range between 1 and $10 \mu \mathrm{m}$. In Fig. $10(\mathrm{~b})$, the width of the tracks is between 20 and $100 \mu \mathrm{m}$. The craters shown in Fig. 10(a) might be in the stage of growing and on the other hand, the tracks shown in Fig. 10(b) might be formed as the sum of random traverse motions. (The SEM picture shown in Fig. 3 reveals that there are several eroded craters within a width of the track.) Although the typical diameter of a cathode spot cannot be determined from these observations, it can be said that the size is less than $100 \mu \mathrm{m}$ but larger than $1 \mu \mathrm{m}$.

Taking the uncertainty of the spot dimension into account, and using the values experimentally obtained as mentioned above ( $i=18 \mathrm{~A}, V=20 \mathrm{~V}$ and $\alpha=1 / 3)$, the density of the heat flux calculated by eq. (1) is in the range between $10^{10} \mathrm{~W} \cdot \mathrm{m}^{-2}$ and $10^{14} \mathrm{~W} \cdot \mathrm{m}^{-2}$. 

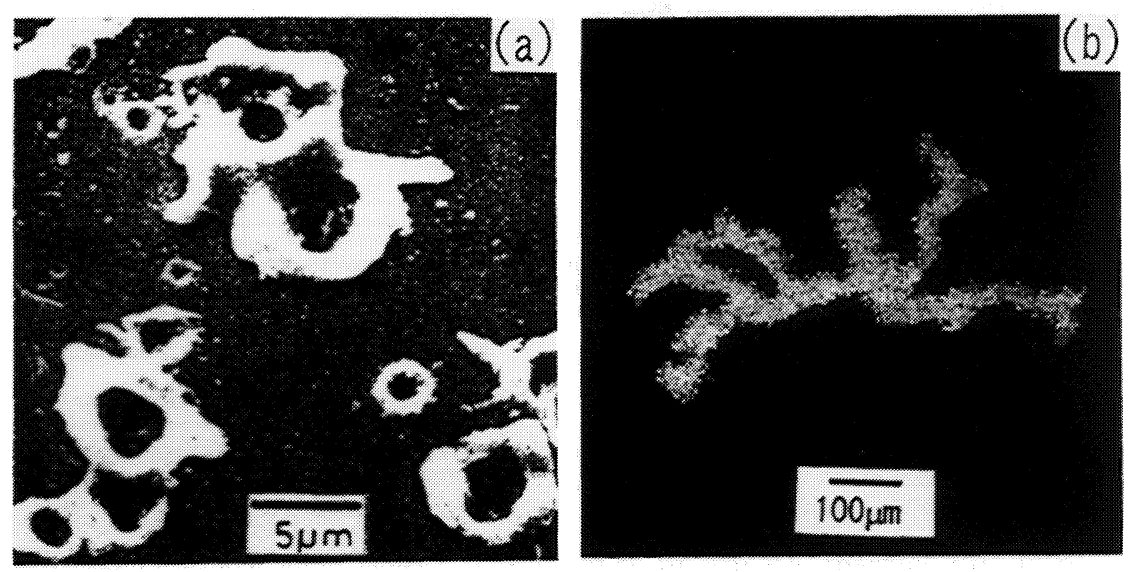

Fig. 10 Track of the cathode spots on the scale surface formed in a pulse arc operation; (a) craters obtained in a short pulse less than $100 \mu \mathrm{s}$ and (b) track obtained in a long pulse of $10 \mathrm{~ms}$. Scale thickness is $5 \mu \mathrm{m}$.

\section{Discussions}

\section{Modeling}

In order to understand the controlling parameters which are responsible to the descaling rate in the vacuum arc treatment, the authors developed a simplified model based on the energy balance at a cathode spot. Schematic illustration of heat flows at the cathode spot is shown in Fig. 11(a). An arc is terminated by several spots on the cathode surface. The current of an individual cathode spot and its area are represented by $i$ and $s$, respectively and $N$ is the number of the spots. The idea on the cathode spot movement is also illustrated in Fig. 11(b).
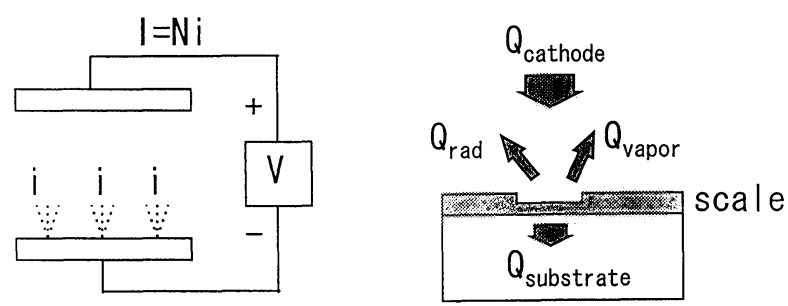

(a)
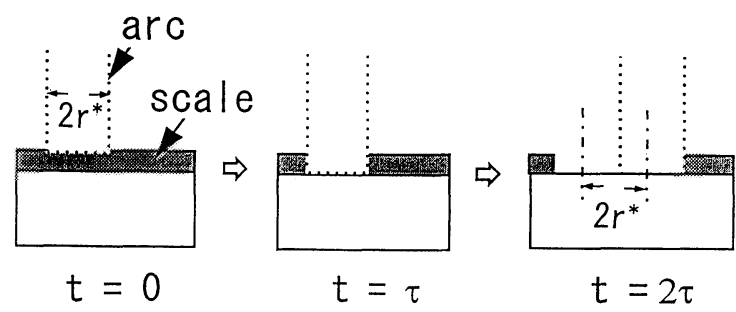

(b)

Fig. 11 Schematic illustration of the basic idea of the modeling on the descaling by the vacuum arc; (a) electric circuit and heat balance at the cathode spot, and (b) assumption of discrete movement of the cathode spot.
Each cathode spot is assumed to move discretely: It stays in one small area during the removal of the oxide on which the arc is terminated, and after the complete removal of the oxide the spot jumps to a new oxide area next to the former one. In this figure, at $t=0$, an arc spot with the radius of $r^{*}$ forms on the oxide, and at $t=\tau$, all the oxide under the cathode spot is removed, then the new spot is formed on the oxide next to the former spot. In this paper, $\tau$ is called a characteristic descaling time. The balance of energy flow at each cathode spot is expressed by the following relation:

$$
Q_{\text {cathode }}=Q_{\text {vapor }}+Q_{\text {radiation }}+Q_{\text {substrate }} \text {. }
$$

The heat flux from the arc to the cathode, $Q_{\text {cathode }}$, is written as

$$
Q_{\text {cathode }}=\alpha(i V) \text {. }
$$

The flux conveyed away by the vapor of the oxide, $Q_{\text {vapor }}$, is represented by

$$
Q_{\text {vapor }}=s(\mathrm{~d} D / \mathrm{d} t) H_{\mathrm{v}},
$$

where $H_{\mathrm{v}}$ and $D$ symbolize the amount of the heat necessary for the evaporation of the unit volume oxide, and the thickness of an oxide, respectively. The heat flux radiated from the cathode spot, $Q_{\text {radiation }}$, is approximated by

$$
Q_{\text {radiation }}=s \sigma T_{\mathrm{v}}^{4} \text {, }
$$

where $\sigma$ and $T_{\mathrm{v}}$ represent Stefan-Boltzmann constant and an evaporation temperature of the oxide, respectively. The heat flow to the cathode substrate by heat conduction, $Q_{\text {substrate }}$, is expressed in the following form:

$$
Q_{\text {substrate }}=s \kappa \operatorname{grad} T,
$$

where the thermal conductivity is represented by $\kappa$. The variation in $D$ with time is obtained by solving eq. (2). As $Q_{\text {radiation }}$ is small compared with other terms in eq. (2), it is neglected. One dimensional heat conduction is assumed in eq. (6) for the simplification of the modeling. A characteristic descaling time denoted by $\tau$ corresponds to the period necessary for the change of $D$ from initial oxide 
thickness $D^{*}$ to zero. Under the boundary condition that the surface temperature is kept $T_{\mathrm{v}}$, the following approximate form is obtained for $\tau$ :

$$
\tau=D^{*} H_{\mathrm{v}} /\left(E-2 \kappa T_{\mathrm{v}} / D^{*}\right),
$$

where $E$ represents the energy flux density at the cathode spot defined by eq. (1). The macroscopic speed of the cathode spot movement, $U$, can be expressed as

$$
U=2 r^{*} / \tau,
$$

where $r^{*}$ denotes the diameter of the cathode spot. By using eqs. (1) and (7), eq. (8) is rewritten in the following equation:

$$
U=2(\alpha i V / \pi E)^{0.5}\left(E-2 \kappa T_{\mathrm{v}} / D^{*}\right) / D^{*} H_{\mathrm{v}} .
$$

Then, the total removal rate of the oxide layer by the group of cathode spots becomes:

$$
\mathrm{d} S / \mathrm{d} t=N S / \tau=N(\alpha i V / E)\left(E-2 \kappa T_{\mathrm{v}} / D^{*}\right) / D^{*} H_{\mathrm{v}},
$$

where $S$ represents the total descaled area of the cathode spots. In the case of high density energy flux $\left(E \gg \kappa T_{\mathrm{v}} /\right.$ $\left.D^{*}\right)$, the speed of the cathode spot movement and the removal rate of the oxide layer are expressed by

$$
U=2(\alpha E i / \pi)^{0.5} V^{0.5} / D^{*} H_{\mathrm{v}}
$$

and

$$
\mathrm{d} S / \mathrm{d} t=\alpha I V / D^{*} H_{\mathrm{v}} .
$$

It is expected from eq. (11) that the speed of the cathode spot movement increases with the increase of the heat flux density and with the decrease of the scale thickness. From eq. (12), the descaling rate is predicted to vary in proportion to the total arc current and in inverse proportion to the thickness of the oxide as far as the current density of the cathode spot is high. Equation (10) reveals that the removal of the oxide layer does not occur at the heat flux density less than a certain critical value written by

$$
E_{\text {critical }}=2 \kappa T_{\mathrm{v}} / D^{*} \text {. }
$$
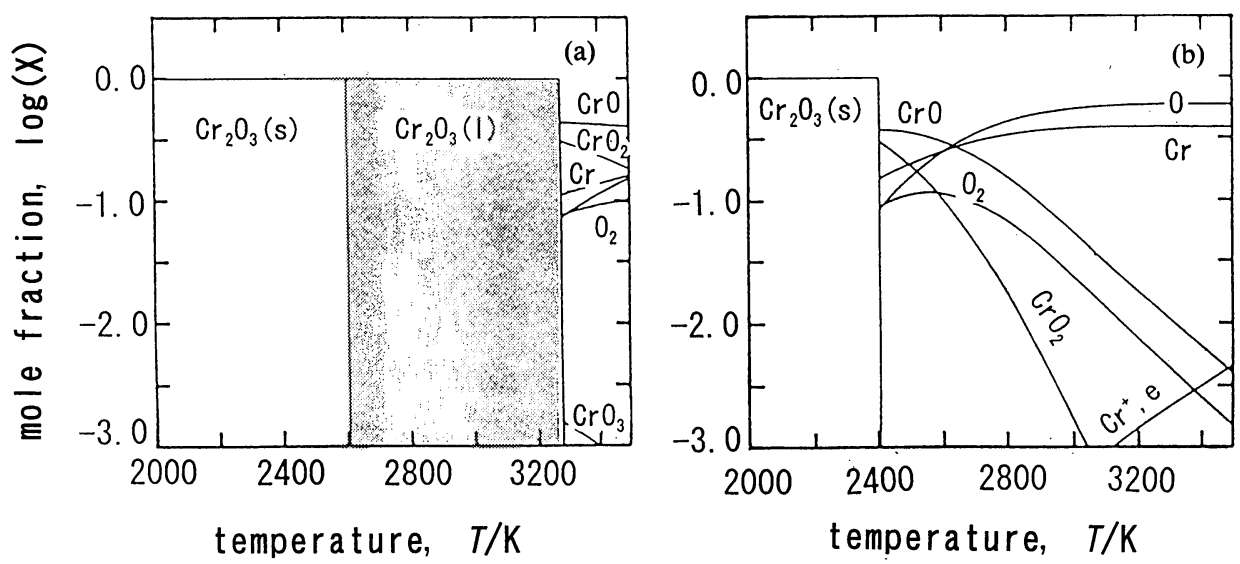

Fig. 12 Phase changes of the $\mathrm{Cr}_{2} \mathrm{O}_{3}$ with temperature at different pressures; (a) $10^{5} \mathrm{~Pa}$, and (b) $10^{2} \mathrm{~Pa}$

\section{Energy necessary for the removal of the oxide}

To simplify the model, the chemical composition of the oxide is assumed $\mathrm{Cr}_{2} \mathrm{O}_{3}$ for the test pieces of the stainless steel. $H_{\mathrm{v}}$ in eq. (4) is also assumed to the energy necessary for the following decomposition reaction of $\mathrm{Cr}_{2} \mathrm{O}_{3}$ of unit volume solid and heating the vaporized gas to $3000 \mathrm{~K}$.

$$
\mathrm{Cr}_{2} \mathrm{O}_{3} \text { (solid) } \rightarrow 2 \mathrm{Cr} \text { (gas) }+6 \mathrm{O} \text { (gas) }
$$

The path from $\mathrm{Cr}_{2} \mathrm{O}_{3}$ to $\mathrm{Cr}$ and $\mathrm{O}$ depends on the pressure. The phase diagrams of $\mathrm{Cr}_{2} \mathrm{O}_{3}$ at various pressures are calculated by using thermodynamic program "SOLGASMIX" (14). Under the pressure of $10^{5} \mathrm{~Pa}$, solid $\mathrm{Cr}_{2} \mathrm{O}_{3}$ melts at about $2600 \mathrm{~K}$ and vaporizes at about 3200 $\mathrm{K}$. However under the pressure of $10^{2} \mathrm{~Pa}$, solid $\mathrm{Cr}_{2} \mathrm{O}_{3}$ decomposes to gas species directly at $2400 \mathrm{~K}$ without melting. The phase diagram of $\mathrm{Cr}-\mathrm{O}$ system at $P=10^{2} \mathrm{~Pa}$ and that at $P=10^{5} \mathrm{~Pa}$ are shown in Fig. 12. Taking the change in the phase diagrams with pressure into account, the energy necessary for the decomposition of $\mathrm{Cr}_{2} \mathrm{O}_{3}$ and heating to $3000 \mathrm{~K}$ is estimated to be $100 \times 10^{9} \mathrm{~J} \cdot \mathrm{m}^{-3}$ under the experimental condition.

\section{Numerical calculation of the model and comparison with experiment}

Figure 13 shows the predicted characteristic descaling time as a function of heat flux density at the cathode spot. Calculation was carried out for the removal of $\mathrm{Cr}_{2} \mathrm{O}_{3}$ of $5 \mu \mathrm{m}$ in thickness under the following assumptions; $\alpha=1 / 3, \quad V=20 \mathrm{~V}, \quad i=18 \mathrm{~A}, \quad T_{\mathrm{v}}=2400 \mathrm{~K}$, and $H_{\mathrm{v}}=100 \times 10^{9} \mathrm{~J} \cdot \mathrm{m}^{-3}$. The critical heat flux density, $E_{\text {critical }}$, was estimated to be $9.6 \times 10^{9} \mathrm{~W} \cdot \mathrm{m}^{-2}$. Based on the same assumptions, eq. (12) at $I=200 \mathrm{~A}$ was calculated. A solid line in Fig. 14 represents the predicted total descaling rate as the function of scale thickness. Experimental descaling rates at $I=200 \mathrm{~A}$ are also plotted in the same figure and compared with the theoretical ones. Experimental results qualitatively satisfy the predicted linear relation between the removal rate and the thickness of the oxide layer. However, there exists the considerable 


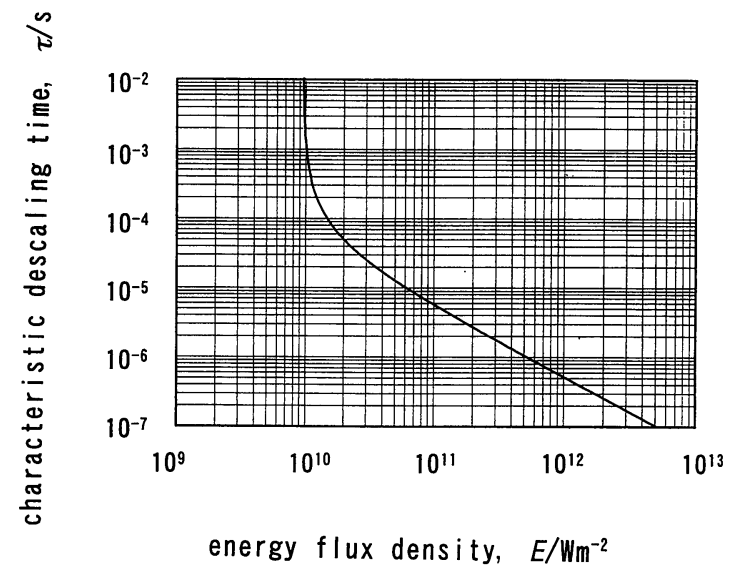

Fig. 13 Predicted change of characteristic descaling time with the energy flux density. Scale thickness is $5 \mu \mathrm{m}$.

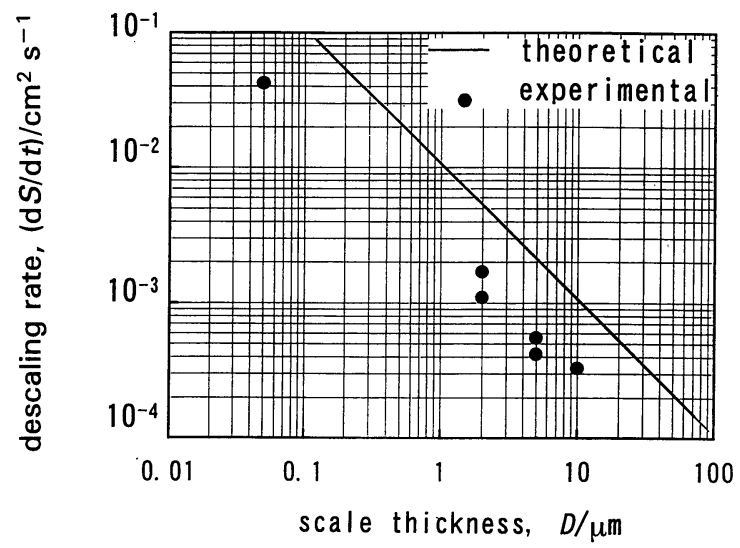

Fig. 14 Comparison of the descaling rate predicted from the modeling with that obtained by experiment at an arc current of $200 \mathrm{~A}$.

difference quantitatively. Because of the simplification in the modeling, exact agreement is not expected between numerical prediction and experimental data. The assumption of one dimensional heat conduction used in the modeling may lead to the overestimation of the descaling rate. There is some doubt in the assumption that the condition of $E \gg \kappa T_{\mathrm{v}} / D^{*}$ is applicable to all of the cathode spots. If some of the cathode spots do not satisfy this assumption, it also leads to overestimation in the total descaling rate. Further investigation is needed on the deviation of the heat flux from the average for each cathode spot.

\section{Conclusions}

In the present work, fundamental behavior of the cathode spots in vacuum arc descaling was studied experimentally. Properties of the cathode spots are summarized as follows:

(1) Multiple arc spots are formed on the cathode surface. The number of the cathode spots increases in proportion to the arc current. For the cathode of a stainless steel covered with an oxide layer, the current of each cathode spot is $18 \mathrm{~A}$ on the average.

(2) The density of heat flux at each cathode spot is estimated to be larger than $10^{10} \mathrm{~W} \cdot \mathrm{m}^{-2}$ but smaller than $10^{14} \mathrm{~W} \cdot \mathrm{m}^{-2}$.

(3) The cathode spots are formed selectively on the oxide and travel on the cathode removing the oxide from the surface. Owing to the intense heat flux at the cathode spot, the oxide is evaporated in a short time.

(4) The removal rate of the oxide is in proportion to the total arc current and in inverse proportion to the thickness of the oxide layer.

(5) The arc sustaining voltage increases slightly when the descaling action finishes.

In order to understand the parameters which govern the descaling action, a simplified model was developed by using a relation of the energy balance at the cathode spot. From the analyses of the modeling, following predictions were obtained:

(6) There exists a critical density of the heat flux below which evaporation of the oxide does not occur and most of the input energy is lost by the heat conduction to the substrate.

(7) The traveling velocity of the cathode spot depends on the heat flux density and the thickness of the oxide layer. The increase of the flux density results in the increase of the velocity. The relation between the velocity and the thickness of the oxide layer is inversely proportional.

(8) If the density of the heat flux is much larger than the heat conduction to the substrate, the descaling rate is in proportion to the total arc current and in inverse proportion to the thickness of the oxide layer, as observed in the experiment.

\section{REFERENCES}

(1) J. M. Lafferty: Vacuum Arcs, A Wieley-Interscience Publication, (1979), p. 120.

(2) M. P. Reece: Proceedings I.E.E., 110 (1963), 793.

(3) C. W. Kimblin: J. App. Phys., 44 (1973), 3074.

(4) M. S. Agarwal and R. Holms: J. Phys. D, 17 (1984), 743.

(5) R. I. Hatschek: Am. Mach., 127 (1983), 129.

(6) S. Vuorinen, E. Niemi and A. S. Korhonen: J. Vac. Sci. Technol., A, 3 (1985), 2445.

(7) H. Randhawa and P. C. Johnson: Surface and Coating Technol., 31 (1987), 303.

(8) A. E. Guille and B. Juettner: IEEE Transactions, PS-8 (1980), 259.

(9) H. D. Steffens: Proc. 9th Int. Thermal Spray Conference, Welding Institute of Germany, (1980), p. 420.

(10) K. Takeda, M. Ito and S. Takeuchi: Pure and Appl. Chem., 62 (1990), 1773.

(11) A. Itoh, K. Takeda, M. Ito and M. Koga: Proc. National Thermal Spray Conference, Longbeach, The American Welding Society, (1990), p. 20.

(12) Y. Itoh, M. Saito, K. Honda and M. Miyazaki: J. Soc. Mat. Sci. Japan, 42 (1993), 874.

(13) Arifov Institute of Electronics: Patent Application, JP N 2221389, filed 24, Aug., (1990).

(14) G. Erickson: Acta Chem. Scand., 25 (1971), 265. 